\title{
Developing a Taxonomy and Model to Transfer and Assess Best Practices for Supply Chain Management
}

\author{
Myrna Flores ${ }^{1}$, Ana Mendoza ${ }^{2}$, Victor Lavin², and Benito Flores ${ }^{2}$ \\ ${ }^{1}$ Research and Networking, Processes and IT, \\ CEMEX Global Center for Technology and Innovation, \\ CEMEX Research Group AG, Römerstrasse 13 CH-2555 Brügg, Switzerland \\ ${ }^{2}$ Departamento de Ingeniería Industrial, \\ Universidad de Monterrey (UDEM), Mexico \\ myrnafatima.flores@cemex.com, toryana@hotmail.com, \\ victor.lavin@gmail.com, bflores@udem.edu.mx
}

\begin{abstract}
Supply Chain Management can be briefly defined as the orchestration of a network of entities such as suppliers, distributors and clients to achieve a common goal: delivering cost efficient products and services exceeding customers' expectations. Therefore, firms should consider all those End-to-End processes enabling an efficient integration and interoperability of partners collaborating in such Supply Chain when designing their Business Process Architecture (BPA). One key enabler to accomplish this goal is the identification, documentation and sharing of best practices. This paper describes the outcomes of a collaborative project carried out by CEMEX Research Group and the Universidad de Monterrey (UDEM), which focused on developing taxonomy to document best practices for the supply chain management together with a generic model to evaluate their level of implementation.
\end{abstract}

Keywords: Best Practices, Supply Chain Management, SCOR, Taxonomy.

\section{Introduction}

Today, competition plays one of the most important roles within the industrial sector as companies are struggling every day to position themselves in existing and new markets, providing their customers new or improved products or services with the best possible quality, lower costs and in a global way. In order to offer such products and services, reducing costs and improving delivery times, firms are forced to go beyond their boundaries; integrating customers and suppliers in their End-to-End (E2E) processes structure [1]. According to Hammer and Stanton [2], executives do not see anymore their organizations as sets of discrete units with well-defined boundaries. Instead, they see them as flexible groups of intertwined work and information flows that cut horizontally across business, ending at points of contact with suppliers and customers.

In order words, firms need to go beyond their own company and orchestrate the complete supply chain in a more effective way. This is where a Business Process Architecture (BPA) is needed to map, analyze, improve and monitor End-to-End 
business processes to determine what improvements could be carried out and define new initiatives considering both suppliers and customers. The procedure is to identify opportunity areas, analyze their economic impact and then define and carry out improvement projects to increase profits for total customer satisfaction.

One critical enabler for the development and improvement of such E2E business processes are best practices. These latter can be defined as a proved method, procedure or activity that has provided the best possible outcomes or improvement when being applied to a specific process. For instance, two successful and very well known examples of best practices implementation are: a) the Toyota Way, which has been proved to be a best practice for lean production reducing waste, costs and increasing adding value activities [3] and b) Six Sigma which has proved not to be only a structured statistical methodology to improve and design of processes and products, but also a standard way to communicate and manage projects internally; bringing economic returns to companies such as Motorola and General Electric [4].

As a consequence, there is an increasing interest from both large and small organizations to develop, implement and continuously upgrade industrial best practices [5]. In fact, Arthur Anderson has created a "Global Best Practices" division, which performs "best practice" audits for companies to identify areas for improvement [6].

Thus, in order to identify, document and transfer such best practices, a five step methodology can be considered: 1) research for those proved industrial best practices, 2) select the ones that are best aligned to the firm strategy, 3) assess their potential business impact, 4) transfer them internally in a successful way and 5) measure their returns after implemented. In such a context, there is a need to identify, document, share, adapt, reuse and implement best practices in a systematic manner. Therefore, a collaborative research project between CEMEX Research Group (CRG) and the Universidad de Monterrey (UDEM) was defined to identify best practices that have proved to increase the supply chain performance and document them in a standard way to diffuse and implement them internally in CEMEX.

\section{Research Methodology}

The defined CEMEX - UDEM collaborative research project objectives were:

- Search, identify and select supply chain best practices, applying a process perspective. In this case the SCOR standard reference model was applied.

- Design a taxonomy to document the selected best practices.

- Document the selected best practices to share them in a global repository under construction (SMARTBRICKS) by the international DiFac project.

- Develop an evaluation model to map the implementation and improvement of supply chain best practices and define new initiatives.

The LEAD methodology, developed in CEMEX Research Group [7], which proposes four stages for collaborative research with external partners (Learn, Energize, Apply and Diffuse) was applied to manage this collaborative research project with UDEM as follows: 


\section{1) LEARN}

- The research project objectives and research questions were defined. CEMEX and UDEM agreed on the objectives and expected deliverables and deadlines.

- An extensive literature review on supply chain and best practices was carried out. CEMEX suggested using the well known SCOR generic model to map best practices under a process perspective.

2) ENERGIZE

- An initial list of more than 100 supply chain best practices was identified under the three key processes of the SCOR model: Source, Make and Deliver and for Make to Stock (MTS) and Make to Order (MTO) manufacturing typologies.

- A survey questionnaire was designed to gather information from experiences from several companies in Monterrey to map recognized best practices in the supply chain.

- Face-to-face interviews were carried out to companies in Monterrey by UDEM's team

\section{3) APPLY}

- The interviews' and survey data was analyzed to identify the best practices which proved business results in the interviewed companies. Twenty best practices were selected and documented for the development of a best practices digital library in CEMEX

- A taxonomy to document and share supply chain best practices was designed.

- A model for best practices assessment was developed

\section{4) DIFFUSE}

- During this last phase, diffusion of results are carried out within CEMEX, in scientific journals and international conferences.

The deliverables of this collaborative research project are: 1) the design of a taxonomy to document best practices in the supply chain, 2) to create an evaluation model to assess the level of implementation of best practices in CEMEX and 3) the documentation of the selected best practices for the supply chain as the foundation to create an open repository or digital library where employees could have global access to learn about such best practices.

\section{Identifying and Documenting Supply Chain Management (SCM) Best Practices: Towards A Standard Taxonomy}

Supply Chain Management is the total manage of a network of facilities and distribution options in a partnership between a consumer, distributor and manufacturer with the purpose of transfer and exchange information and physical goods for the supplier's suppliers to their customer's customers ensuring the right goods in the most efficient manner, reached accurately wherever they are required in a company and beyond [8].

An excelling supply chain performance is essential to meet customers' requirements, therefore, it is important to provide CEMEX employees a tool to enable them 
to learn, use, implement and continuously update in a global, dynamic and collaborative way, supply chain practices. This latter can be possible by developing a digital library to diffuse and reuse documented best practices, facilitating workers to evolve into "knowledge workers" to learn and implement supply chain best practices in their daily activities.

\subsection{Applying the SCOR Framework}

The Supply Chain Operational Reference Model (SCOR) is defined as a process model combining elements of business process engineering, benchmarking, and best practice into a single framework [9]. It was designed to encompass the supply chain from the supplier's supplier to the customer's customer. It integrates business processes definitions, performance indicators and best practices. Under the SCOR model, best practices are defined as successful standard operating procedures for a given process. Business analysts observe and evaluate various companies and gather information on what works best. SCOR is based on three process types: Planning, Execution and Enable. The execution process is then divided into Source, Make, Deliver and Return [10]. One additional fact is that the Source, Make, Deliver processes have been documented by manufacturing typologies, in other words: Make to Stock (MTS), Make to Order (MTO) and Engineering to Order (ETO).

\subsection{Identifying, Selecting and Documenting Supply Chain Best Practices}

Fifteen filled-in surveys were obtained with the aim of confirming the theoretical study conducted to understand the relevance of best practices within the supply chain. The survey consisted of two main parts:

1) Discussion and analysis of best practices in the supply chain: This part of the survey aimed to obtain from supply chain experts, from different firms, the importance of best practices listed. Respondents were asked to carefully analyze, select and rank 20 best practices, from a list of 100 identified best practices in supply chain, that according to their work experience and knowledge can be considered as the most strategic to optimize the supply chain and which have provided economic returns in their company. Table 1 shows the twenty selected best practices by the experts.

2) Assessment of best practices within the processes of the SCOR model: In this second step, each expert was requested to assign a value to assess the impact of each of supply chain practice. Values were 7 (high), 5 (medium), 3 (low), 0 (none). The eight companies that responded to the survey in this research project were both local manufacturing and consulting firms in Monterrey (Mexico) with vast experience in supply chain management such as: TERNIUM, AHMSA, CEMEX, TRINITYRAIL, TEKSID, RIMSA, OPTIMA SERVICE and CONSULTORES ASOCIADOS INTEGRA.

3) Selection and documentation of the twenty best practices: Twenty top best practices were identified to optimize the supply chain performance based on the findings of the research (step 2). All these best practices were documented in detail. 
Table 1. Twenty Best Practices identified in the Study

\begin{tabular}{|c|l|}
\hline Number & \multicolumn{1}{|c|}{ B EST PRACTICE S } \\
\hline 1 & Just in Time (JIT) \\
\hline 2 & Benchmarking \\
\hline 3 & KANBAN \\
\hline 4 & Lean Production \\
\hline 5 & Material R equirements Planning (MR P) \\
\hline 6 & Total Quality Management (TQM) \\
\hline 7 & Electronic Data Interchange (E DI) \\
\hline 8 & Forecasting \\
\hline 9 & ABC Classification \\
\hline 10 & Enterprise R esource Planning (ER P) \\
\hline 11 & International Organization for S tandardization (IS O) \\
\hline 12 & Outs ourcing \\
\hline 13 & Warehouse Management Systems (WMS) \\
\hline 14 & Total Productive Maintenance (TP M) \\
\hline 15 & Real time inventory control \\
\hline 16 & Route optimization \\
\hline 17 & Distribution R es ource Planning (DR P) \\
\hline 18 & Inventory, cycle counting \\
\hline 19 & Manufacturing Resource Planning (MR P II) \\
\hline 20 & S upplier qualification systems \\
\hline
\end{tabular}

\subsection{Supply Chain Best Practice Taxonomy Design}

To develop the taxonomy to define and document supply chain practices in a standard way, the following elements were taken into consideration:

- Definition of best practice: Description of the meaning of the practice and why the relevance of it within the supply chain.

- Background of the best practice: How and why the best practice emerged, who created it and for what purpose.

- Components of best practice and their definitions: The key factors of best practice, those elements that help the practice to achieve their objectives and have an optimal performance for the supply chain.

- Implementation Methodology: It describes the method of implementation of the best practice.

- Benefits of implementing the best practice: Advantages of its deployment, control and the proper handling of the best practice for the chain.

- Limitations: Restrictions and conditions for the implementation and scope of the practice.

Figure 1 presents and example of how the proposed taxonomy was applied to document one of the identified best practices: lean production. 


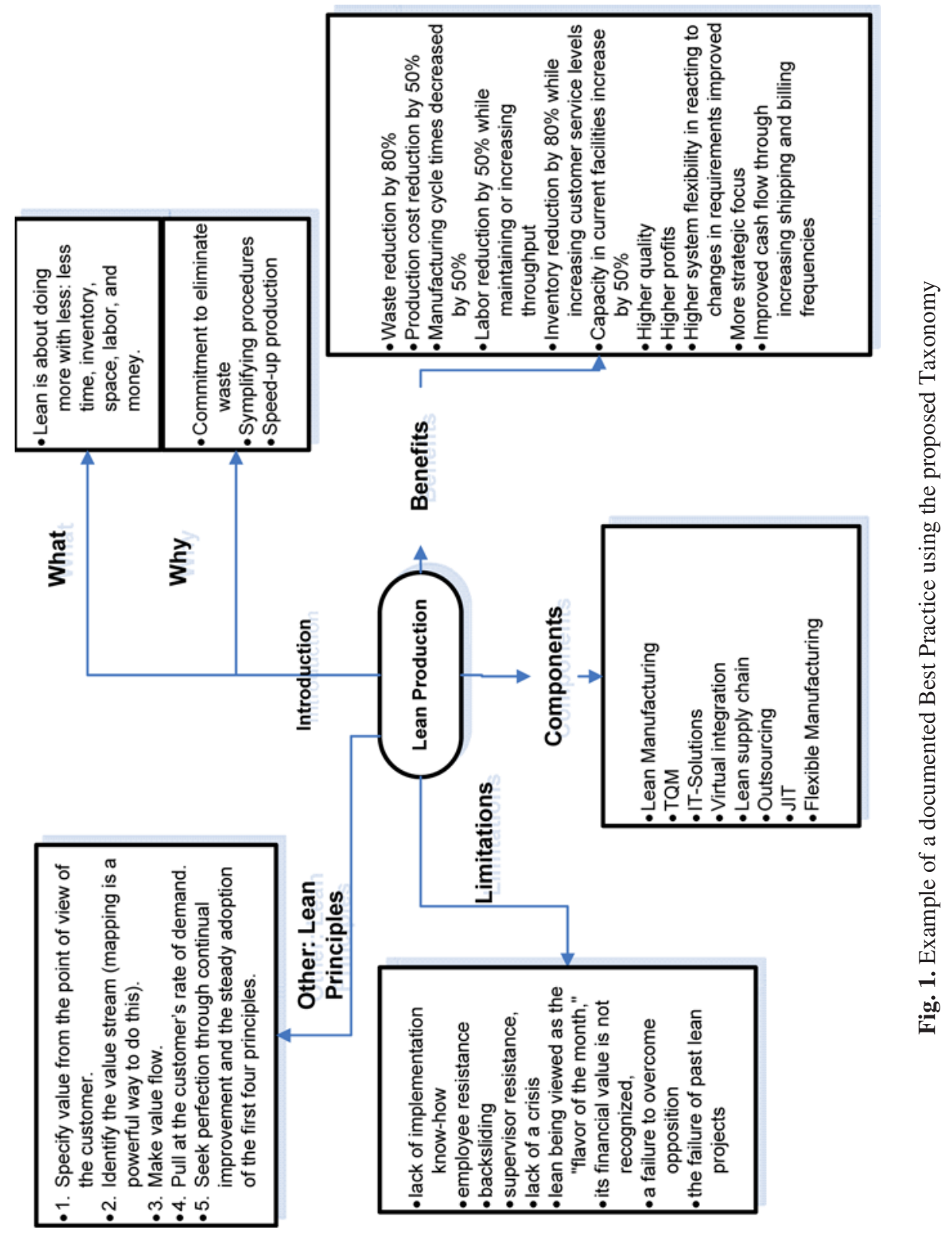




\section{Best Practices Assessment and Evolution Model}

To evaluate the level of best practices implementation, a Supply Chain's Best Practices Evaluation Model was developed as a tool to identify opportunity areas for improving the performance of the supply chain aligning them to the business strategy. The model consists of three stages:

1) Assessment of the "AS IS" implementation level of best practices: During this first step, the model focuses to assess the level of implementation of the different identified best practices. This assessment consists of six levels ranging from total ignorance of the practice, to a level of maturity of the practice within the process, i.e. a maximum level at which the practice has already given results and could be transferred to other entities. The six implementation levels are:

$\begin{array}{ll}\text { LEVEL } 1 & \text { WE DONT KNOWTHE PRACTICE } \\ \text { LEVEL } 2 & \text { WE KNOWTHE DEFINITION ANDTHE OBIECTIVES OF THE PRACTICE } \\ \text { LEVEL } 3 & \text { WE KNOWHOWTO IMPLEMENT THE PRACTICE WTHA METHODOLOGY } \\ \text { LEVEL } 4 & \text { THE PRACTICE IS IN THE PROCESS OF IMPLEMENTATION } \\ \text { LEVEL } 5 & \text { WE HAVE IMPLEMENTED THE PRACTICE AND HAS PRODUCED RESULTS } \\ \text { LEVEL } 6 & \text { THE PRACTICE IS IMPIEMENTED WTHRESULTS AND HASBEEN IMPRONED }\end{array}$

2) Identification of the level of relevance of best practices "TO-BE" within the supply chain: At this stage of the model, the selected best practices are assessed from 1 to 4 level of strategic relevance in the supply chain being 1 the least important and 4 the most relevant.

3) Developing an Implementation / Results Matrix to define key improvement initiatives: During this third and last step, the results of the previous two stages were mapped within a chart in order to relate the level of implementation ( $\mathrm{x}$ axis) with the strategic relevance of the practice (y axis). In order to support decisionmaking, the chart is divided into four quadrants (Figure 2):

- Improve: The practices located in this quadrant show that the level of implementation is still low and its relevance is high, therefore an opportunity area is detected to improve and speed up the implementation of such practice.

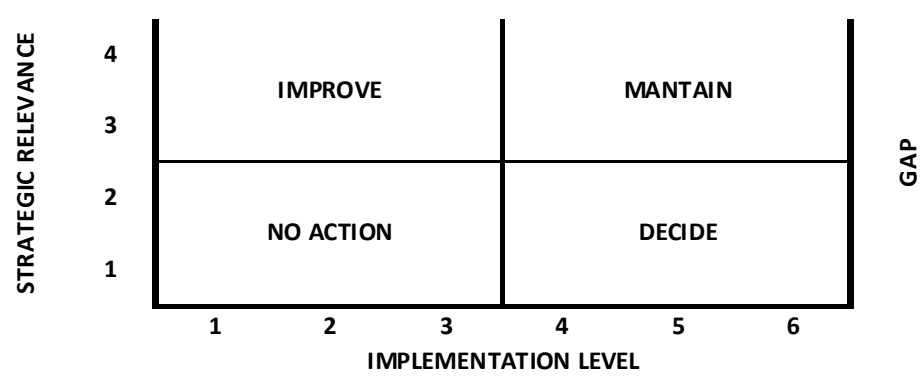

Fig. 2. Best Practices Assessment and Evolution Model 
- Maintain: This quadrant contains those best practices that have been successfully implemented and that are still relevant, so they should be maintained.

- Decide: The practices classified in the third quadrant are of a high level of implementation and low relevance, so the organization should decide to act or not on improving the performance of such practice. In fact, this last quadrant shows those practices which have been implemented but represent a cost as they are not anymore relevant or strategic for the business.

- No Action: This last quadrant reflects that the assessed practice has a low implementation and is not relevant according to the strategy; therefore the model suggests not taking any action.

\section{Conclusion}

Companies need to evolve into fully integrated supply chains, based on the implementation of End-to-End processes. This project concluded successfully proposing a standard taxonomy to document supply chain best practices and a model to assess their implementation and evolution according to the business strategy. The documentation of such best practices will enable knowledge workers in CEMEX to learn and improve their competences managing in a better way supply chain processes integrating suppliers and customers.

\section{References}

1. Flores, M.: End-to-End Process Management, Towards a Process Centric Organization. In: Internal CEMEX Whitepaper (2008)

2. Hammer, M., Stanton, S.: How Enterprises Really Work. Harvard Business Review (1999)

3. Liker, J.K.: The Toyota Way, 14 Management Principles. Tata McGraw-Hill Publishing Company Limited (2004)

4. Pyzdek, T.: The Six Sigma Handbook, A Complete Guide for Greenbelts, Blackbelts, and Managers at All Levels. McGraw-Hill Professional Management (2003)

5. Bogan, C., English, M.: Benchmarking for Best Practices: Winning through innovative adaptation. McGraw-Hill, New York (1994)

6. Hiebeler, R., Kelly, T., Ketteman, C.: Best Practices: Building Your Business with Arthur Andersens' Global Best Practices. Simon \& Schuster, New York (1998)

7. Flores, M.: The LEAD Research Methodology to manage collaborative open innovation projects, CEMEX internal document (2008)

8. Towill, D., Naim, M.: System Dynamics and Lean Supply Chains. In: 26th International Symposium on Automotive Technology and Automation, Aachen, Germany (1993)

9. Supply Chain Council, Supply Chain Operations Reference-model framework (1996), http: / / www . supply-chain.org/

10. Bolstorff, P., Rosenbaum, R.: Supply Chain Excellence: A Handbook for Dramatic Improvement using the SCOR Model. American Management Association, New York (2003) 